\title{
Build Low Cost 3D Delta Printer using Fused Deposition Modeling Technology
}

\author{
Abubaker Nooralhoda Ahmed Altayeb \\ Dept. of Measurement and Control technology \\ Northwest Normal University, \\ Lanzhou, China
}

\begin{abstract}
Additive Manufacturing (AM) or "3D Printing" is becoming more common around the world, covering almost the entire mechanical field. This paper presents the process of manufacturing a 3D Delta printers via Fused Deposition Modeling (FDM) using unexpansive materials, the 3D physical prototypes can dissolve the solid material into a liquid and then they build layers on top of each other to give the final form, originally 3D printing was invented by Charles W. (Chuck) 1984. [7-1]

The 3D Delta has three arms on the rails, moving up and down independently, controlling the head of the printer, this process is called the Cartesian coordinate system. Also it uses trigonometric functions based on the angle, which allow the arms to create and determine the precise location of the print head within the 3D print space. Delta printers have many advantages compared to other Cartesian printers such as, combining speed, accuracy, and cheaper assembly mate.
\end{abstract}

Keywords - Additive Manufacturing, Delta printer, Fused Deposition Modeling, Cartesian system.

\section{INTORDUCTION}

Recently, Arduino and RepRap communities have had an increasing progress. Those devices conceder as Open Source development model; and the Projects designed by these devices are considered to be under the umbrella of the GNU General Public License, this allows all users to have quick access and continuous improvement of these devices. The objectives of this process are to produce $3 \mathrm{D}$ printers that can reproduce themselves and use an Open Source software for everyone.

The Delta 3D printers "Deltabots" are distinct from the rest of other Cartesian printers as it is printers use a radically different architecture for their 3D positioning system.

Cartesian system can be described as a coordinate system that identifies any point in a plane with a distinctive way across a set of numerical coordinates which employed distances to the point

from two fixed perpendicular oriented lines, dignified in

the same unit of length. Where the $\mathrm{X}$-axis moves horizontally forward or backwards, and the $\mathrm{Y}$-axis moves vertically in the left or right direction, and the $\mathrm{Z}$ axis moves up or down. Delta 3D printer also uses three control arms that are respectively named $\mathrm{X}, \mathrm{Y}$ and $\mathrm{Z}$ which connected to the print head to control the positioning of the print head. The Delta has light axes and thus produce greater speed and precision as well as a

\author{
Awab Azhari Abdelgader Elagib \\ Dept. Human Recourses Management \\ Northwest Normal University, \\ Lanzhou, China
}

non-moving build platform, so it does not require moving the built platform to build the form, resulting in inaccurate printing and the appearance of distortions in the model, especially if the model is of high length. Delta printing on conventional printers requires other printers to have a move rule, which all depends on the threaded rods and nuts which limits its speed, but makes it is easier to maintain because of the spaces between the moving parts. This printer is controlled using two printed circuit boards (PCB); first board is a microcontroller (Arduino) and the other covers the power electronics. Regarding the Arduino is a flexible based platform, which makes using hardware and software easy.

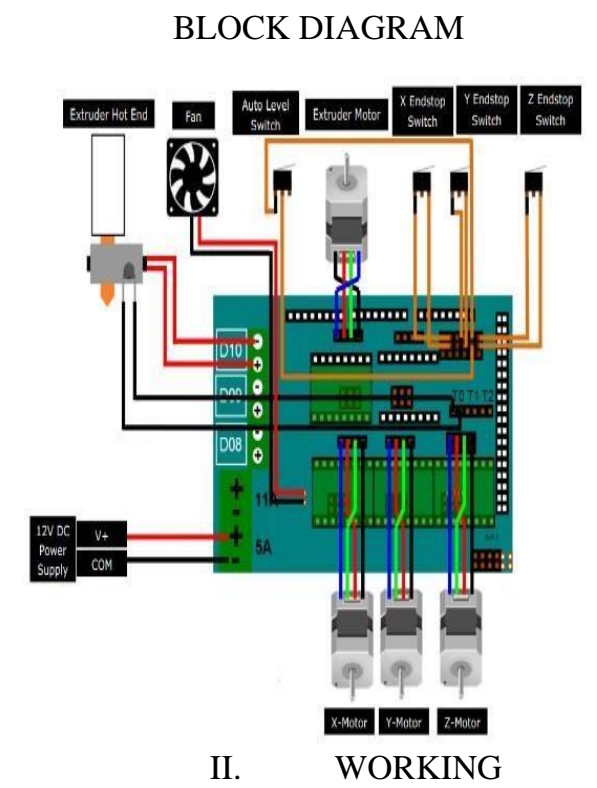

The 3D Delta printer is built in three stages 


\section{FLOW CHART}

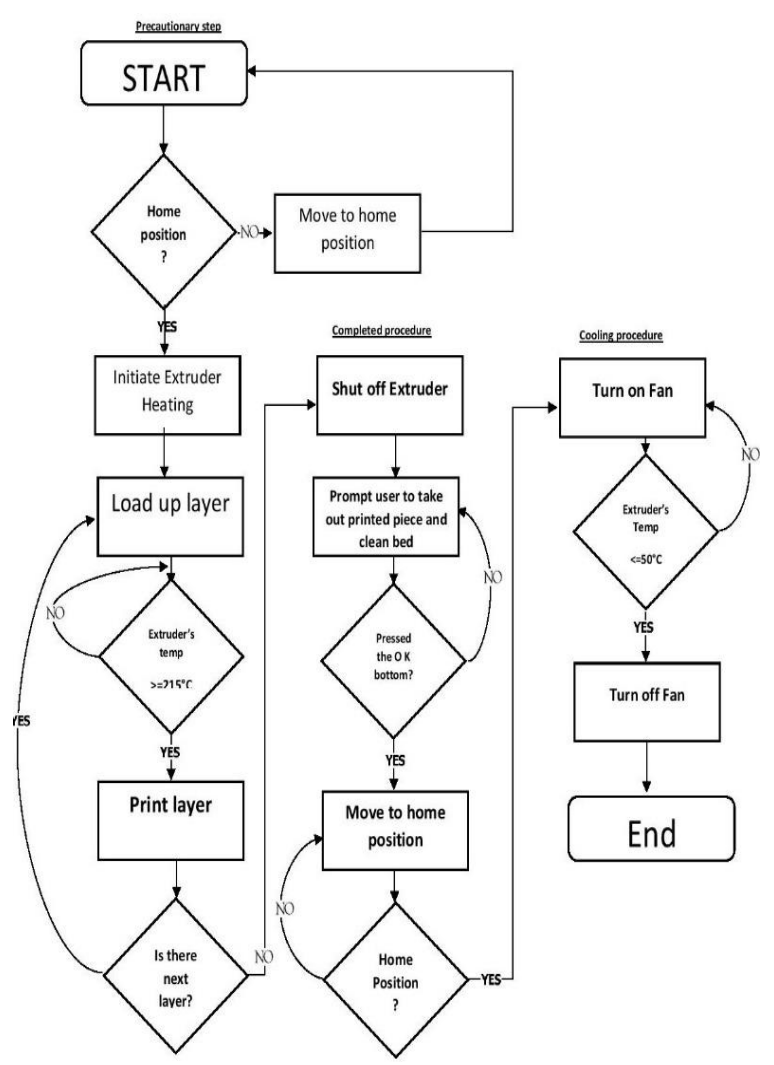

\section{A. Mechanical build}

Wood and Steel were selected as basic materials for the construction of the model. Wood is chosen because it is easy to form and modify, and the steel because it is a cheap and available force.

Several devices and components were purchased:

1- 6 X $70 \mathrm{~cm}, 16 \mathrm{~mm}$ steel Rods.

2- $6 \mathrm{x}$ linear bearings to fit steel rods.

3- $6 \times$ Arm rods with ball joints.

4- 3 x 1210 mm length 6wide GT2 pitch (2) belts 5$3 \times$ Aluminum GT2 pulleys for the stepper motors.

Starting with The "14mm thickness" wood panels were cut according to the designs to build the base, roof, hinges and head of the printer and then make the cavities necessary to pass the wires and install the End stops. After that the three motors are installed in the machine roof, the end of the brake and the material carrier used for printing. Then the steel bars were fixed to build the base axes X, Y and $\mathrm{Z}$, afyer that openings were sealed with a plastic board. Later the arms were assembled and connected to the hinges using screws and then the arms are connected to the printer's head. The arms of each of the 3 sides meet in the middle where the hot end is connected. Finally the belts are connected with the wheels, the motors and the final form assembly of the printer.

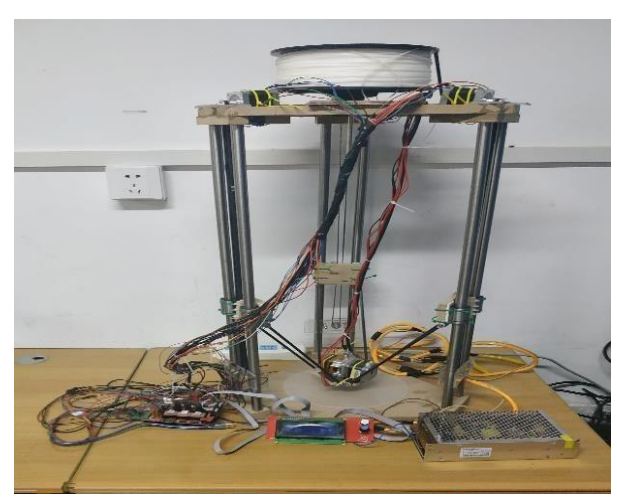

Figure (2) (Delta) 3D printer model

\section{B. Electrical build}

The electronic construction has been done after many devices have been assembled and connected to each other and these devices are:

1- 1x Arduino Mega 2560 microcontroller Board.

2- 1 x Ramps 1.4 set that's complete.

3- 3 x High Torque Hybrid stepper Motors sy42sth47_1684a

4- Geeetech 3D Printer Accessories 3d Printer Head 3d Print Head MK8 Extruder Full Metal.

5- $1 \times$ LCD and SD card panel with plugs into the ramps

6- $3 \times$ Mechanical End stops

7- Minbo 12V 20A Surveillance Camera LED Universal 240W Centralized Power Supply Aluminum Housing Mesh Switching Power Supply.

8- Heated bed PCB MK2Y 200mm, 12 V.

9- A good selection of cables.

Starting with the Arduino panel was equipped with the motor drivers in the Arduino panel according to the data sheet instructions and then connected the four motors with the Arduino panel. After that the End stops are connected with the Arduino panel and LCD screens; the board was connected to the power source. The Arduino was connecte through a USB connection to the computer to load the application on it. It can be noted that after building the prototype of a threedimensional printer, the pieces can be printed to replace the wooden and plastic parts used, to produce the first printer a new printer and this type is called RepRap (self-replicating rapid per) 3D printers [2]

- $\quad$ Steps per millimeter: Steps per millimeter calculate the number of electrical pulses - one for each step - sent through microcontroller "Arduino" to the motor driver to get the desired distance in the end . There are generally two equations for calculating steps per millimeter:

1- To calculate the movement of the axes $\mathrm{X}, \mathrm{Y}$ and $\mathrm{Z}$ :

Steps per $\mathrm{mm}=($ motor steps per rev $*$ driver micro step $) /($ belt pitch $*$

pulley number of teeth)

(2) 
2- To control the flow of printed material from the

Extruder:

Extruder steps per $\mathrm{mm}=$

$(($ motor steps per rev * driver micro step $) *($ big gear teeth / small gear teeth $))$

(Drive pulley effective diameter $* \mathrm{Pi}$ ) (1)

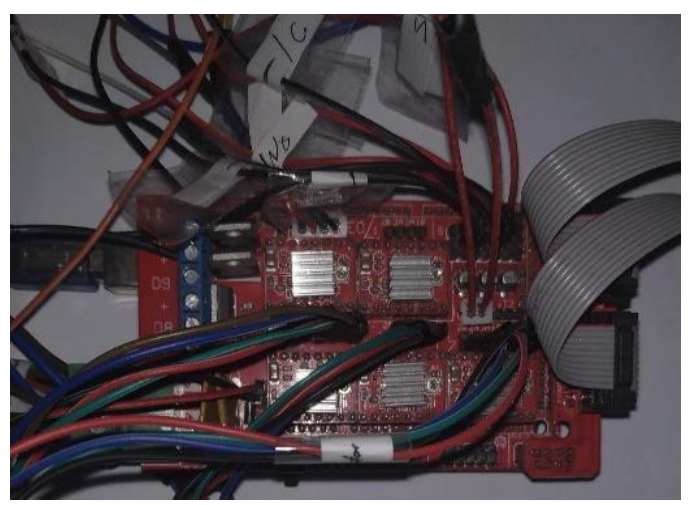

Figure (2): real Arduino wiring for 3D-printer.

\section{Software and programming}

Three programs have been selected to complete the printing process:

First program was used is Marlin firmware which control the printer movement and it contains wide options set inside. First, the measurements were entered such as the Confirm Delta Kinematics, steps per milometer, the temperature of the hot end and, other options. Then to use CAD program "Google SketchUp" and This program is used to draw 3D models as mentioned earlier. Finally CAM program "kisslicer" (which used to run the machine and print format) is equipped with control options via $\mathrm{g}$ code and also by which the amendment in the form of printed layers which form.

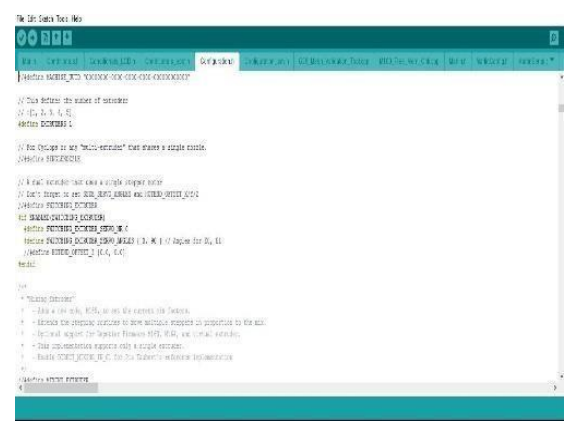

Figure (3): Arduino firmware program

- G-code: G-code can be defined as a set of functions that are used to control different parts of the machine and it's a text file that includes all of the machine instructions to build the file. The use of G-code is not limited to three-dimensional printing machines but relies on a wide range of machines, such as CNC machines, and a new branch has been developed to accommodate threedimensional printers specifically

- $\quad$ Checking the 3D printer: Checking stage comes after the building, wiring and programing of the printer, before the process of printing make sure that all devices operate on the face required if not may cause losing one of devices and must be replaced.

- Filament Types and printing: 3D printing filament is the thermoplastic feedstock for fused deposition modeling 3D printers. The process of 3D printing filament goes across three stages which are: heating, extruding and cooling to convert material used for printing "plastic" into a three-dimensional form. PLA is the martial which used in printing, it has advantages such as easy to print, unexpansive, and it is also solid material, PLA melts at temperature of $180-230 \mathrm{C}^{\circ}$, it should be noted that the more common are diameter $1.75 \mathrm{~mm}$ or $3 \mathrm{~mm}$.

- $\quad$ First step in 3D printing is to design a digital 3D model. Which is simply the process of developing a mathematics representation of any surface of an object in three dimension through the usage of specialized software. CAD (computer aided design) is used as a tool to develop such a model.

- Design slicing: design slicing is the process where the $3 \mathrm{~d}$ model will slicing vertically into many layers so that the printing process will be easier. These layers will be printed one atop the other until the $3 \mathrm{D}$ object is done. This can done using software called slic3r. It is an open source software. The slicing consist of many parts namely

- $\quad$ Post-process the 3D model: Printed forms by FDM technology outweigh the edges where clear classes depending on the precise movement of the axes x/y and homogenization of printed material except printers with a layer height below 20 Microns, and therefore used for finishing operations after printing, Post-process used to Can be easily seen by the disappearance of the edges between the layers to be glaze and gradients is prominent. Some of the most common methods of finishing a print are Sandblasting, Painting and Polishing, Polishing with Tumbler and Lighter/ Fire Based Postprocessing.

\section{CONCLUSION AND FUTURE SCOPE}

There are still many issues to be improved upon in building a 3D-Delta model. The next step that can be done, like the speed of printing, could be improved by increasing the number of headers (Nozzles) in the printer but ultimately a more efficient way is needed. Also for the Finished Product Problem, the printing process must be complete without the need for complementary processes. Beside Energy 
consumption: using less electricity-consuming methods may needed to melt the plastics, to reduce the power consumption and finally unhealthy atmospheric emissions: it is better to install the equipment for the processing of rising gases to make the environment healthier. 3D printing is a distinctive way for the industry because it prints the product according to the consumer's wishes. To be considered as a revolution in technology , and it will increase the popularity of the community to change many usual lineaments of the life.

\section{REFERENCE}

[1] Joan Horvath. Mastering 3D Printing. Apress, 27 August 2014:6-

[2] Sharmila Borah. 3D printer filament length monitor. International Journal of Science, Technology and Society, Vol. 2, 2014:129132.

[3] Elizabeth Matias, Bharat Rao.3D Printing: On Its Historical Evolution and the Implications for Business. Proceedings of PICMET '15: Management of the Technology Age, 2015:551-553.

[4] Feng Lin, Lei Zhang, Ting Zhang, Jia Wang, Renji ZhangInnovative Education in Additive Manufacturing China, 2012:3940.

[5] Prof. Dr.-Ing. Andreas Gebhardt. Understanding Additive Manufacturing Rapid Prototyping, Rapid Tooling and Rapid Manufacturing- Prof. Dr.-Ing. Andreas Gebhard.Hanser, 2011:1215.

[6] Rafiq Noorani. 3D Printing Technology, Applications, and Selection. \& Francis Taylor Group, LLC, 2018:4-6.

[7] Ramya Sai, leela Vanapalli .3D printing technologies in various applications. International Journal of Mechanical Engineering and Technology.IAEME Publication. (IJMET), VOL.7, Issue.3, MayJune 2016:397-407.

[8] Charles Bell. 3D Printing with Delta Printers. Springer Science+Business Media, 2015:71-211.

[9] G. Harsha Vardhan, G. Hari Charan, P. V. Subba Reddy, K. Sampath. Kumar .3D Printing: The Dawn of a New Era in Manufacturing. International Journal on Recent and Innovation Trends in Computing and Communication, VOL.2, Issue. 8, August 2014:2373-2374.

[10] Jie Sun, Weibiao Zhou, Dejian Huang, Jerry Y. H. Fuh and Geok Soon Hong. An Overview of 3D Printing Technologies for Food Fabrication. Springer Science+Business Media New York, 21 April 2015:27-34.

[11] Matthew Scarpino .Motors for Makers a Guide to Steppers, Servos, and Other Electrical Machines. Pearson Education, 2016:5-12.

[12] Matthew Grant. Quick Start for Beginners to Drive a Stepper Motor. Freescale Semiconductor, July 2005:5-9.

[13] Matthew Scarpino .Motors for Makers a Guide to Steppers, Servos, and Other Electrical Machines.by Pearson Education, 2016:55-67.
[14] Marcus Ritland .3D Printing with SketchUp.Packt Publishing, 2014:6-19.

[15] Charles Bell. 3D Printing with Delta Printers. Springer Science+Business Media, 2015:71-211.

[16] Brian Evans. Beginning Arduino Programming. Apress, 2011:35 .

[17] Baljnder .Singh Shahi. Advance manufacturing technology (3DPrinting). International Journal of Mechanical and Production Engineering, VOL 4, Issue 4, April 2016:16-20.

[18] Florin ŞOVĂILĂ, Eng. Claudiu ŞOVĂILĂ and Assist. Prof. PhD Eng. Nicuşor BAROIU. Delta 3D printer .Journal of Industrial Design and Engineering Graphics, VOL 11.Issue 1, July 2016:2933.

[19] Ram Santos, Justin James, Taylor Chris, Stephen Marshall, Pau 1 Maalouf .Delta 3D Printer .Deltronic solution, June 2015:92-94.

[20] Clayton Neff, Matthew Trapuzzano, Nathan B. Crane .Impact of Vapor Polishing on Surface Roughness and Mechanical Properties for 3D Printed ABS. Solid Freeform Fabrication, 2016:2295-2303. 